\title{
Training needs to realise low carbon buildings: the Welsh built environment sector
}

\author{
A. Ruiz del Portal \& J. A. Gwilliam \\ Welsh School of Architecture. Cardiff University, UK
}

\begin{abstract}
The implementation of low carbon strategies in architectural projects requires practitioners to possess current knowledge of this rapidly changing subject. This paper explores the low carbon skills needs of the Welsh building sector and the role of knowledge and training in the delivery of low carbon design. In this context the Welsh Energy Sector Training (WEST) project has developed a course suite that aims to effectively support the ongoing low carbon training requirements of built environment professionals. This training is based on the research outputs from the Low Carbon Research Institute's Convergence Energy Programme (LCRI CEP). Low Carbon Built Environment (LCBE) is one of the themes of research within the LCRI. This research has been led by the Welsh School of Architecture, Cardiff University. The development of WEST LCBE courses is informed by the skills and training needs analysis (STNA) undertaken within the framework of the WEST project, helping to ensure that the courses address the identified needs.

Keywords: low carbon skills, built environment, CPD, training.
\end{abstract}

\section{Introduction}

The UK and Welsh Governments clearly expressed their intention to implement the Low Carbon Agenda. According to Welsh Government [2] Energy Wales: A Low Carbon Transition [3] “...sets out our ambition to harness our energy potential in ways that enable us to transition to a sustainable, low carbon economy." Both Governments have implemented progressive plans for increasing standards to achieve European targets, such as the Welsh Government target of $3 \%$ reduction of greenhouse gas emissions (including $\mathrm{CO}_{2}$ ) per year in areas of devolved competence, ultimately leading to a $40 \%$ reduction by 2020 [2]. The built 
environment is one of the main areas of action to achieve these targets. According to Asset Skills et al. [5] "Almost half of $\mathrm{UK} \mathrm{CO}_{2}$ emissions are connected to our built environment". On the other hand, the EU's Roadmap to a Resource Efficient Europe [6] advises that the reduction of $42 \%$ of final energy consumption, and about $35 \%$ of greenhouse gas emissions could be some of the environmental benefits that the better construction and use of buildings in the EU could bring. The reduction of energy consumption and environmental impact of buildings is already requiring significant changes in the sector and as these demands increase a skilled and knowledgeable Welsh workforce will be required to realise those changes [7] and ultimately enable the realisation of these ambitious targets.

This paper reviews the Welsh built environment sector low carbon educational needs and explains the role of the Welsh Energy Sector Training (WEST) project and its aim to provide the Welsh workforce with relevant training.

\subsection{Low carbon, an opportunity for the Welsh built environment sector}

The construction sector in Wales and the UK has suffered as a result of the economic context particularly in respect of jobs and training [7]. The low carbon economy and the implementation of energy efficiency in the Welsh built environment, particularly in relation to the poor energy performance of the housing stock, is perceived as an opportunity to bring about social, economic and environmental benefits [1,3]. Nonetheless, new commercial opportunities are linked to the development of new products and processes [7]. To harness the full potential of this opportunity all public, private and third sectors need to be committed to the low carbon economy goal. Relevant low carbon policy and research bases for the Welsh built environment are already in place and active, and the public sector is aspiring to create synergies within itself and between the public, private and third sectors towards this goal. However, “...the Welsh professional services sector has been relatively detached from the low carbon agenda. This is having a negative effect for the implementation of a competitive Welsh low carbon economy..." [8]. Industry may be failing to see the long-term benefits of the low carbon economy [1] and therefore resisting the change. Making the industry aware of the predicted significant potential demand from the market [5] and the competitiveness that low carbon skills will provide will be key for the implementation of the Low Carbon Economy. This comes with a requirement for the industry to understand the emerging agenda, acquire necessary skills and build their capacity to deliver market demands $[2,9]$.

\subsection{Welsh Energy Sector Training (WEST) project}

The Welsh Energy Sector Training (WEST) project is the dissemination and training arm of the Low Carbon Research Institute Convergence Energy Program (LCRI-CEP). WEST training has been organised in course suites, one for each of the five LCRI research strands. In the specific case of the WEST low carbon built environment (LCBE) theme the course suite delivers LCRI LCBE research outputs that address the low carbon educational needs of the Welsh built environment sector. "Being able to raise our game in terms of low carbon skills at all levels is 
critical to the Welsh economy...I see the WEST project as having the potential to make a major contribution towards this agenda." Richard Essex, CREW [10].

\section{Understanding the Welsh built environment sector needs}

\subsection{Professionals' profile}

According to BEST [11] "...the majority of the people who will be in employment in 2025 are already in the workplace." Asset Skills et al. [5] highlights that home builders and related trades are the professionals that need to be upskilled. However it also suggests that needs appear beyond the 'build' process. Facilities managers that supervise large buildings, for example, have a strategic and operational function. Similarly, the role of planners is considered to be central to the development of the built environment and as such there is the need for them to understand the requirements of a low carbon economy if they are to respond to governments' agenda by 2016. BEST [11] identifies in table 1 professions relevant to the different stages of the building lifecycle requiring training:

Table 1: $\quad$ Professions to be supported at different building stages [11].

\begin{tabular}{|l|l|l|}
\hline \multicolumn{1}{|c|}{ Design and plan } & \multicolumn{1}{|c|}{ Build } & \multicolumn{1}{c|}{ Manage and use } \\
\hline - Planners/ & - Site/construction & - Facilities managers \\
urban designers & managers & - Surveyors \\
- Architects and & - Building services & - Maintenance \\
Landscape architects & engineers & managers \\
- Engineers: water/ & - Building contractors & - Energy managers \\
energy/building & - Mechanics/fitters & - Estate managers/ \\
services & - Energy installers & landlords \\
- Building control & - Building operatives & - Housing officers \\
officers & & - Estate agents \\
- Energy assessor/planner & & - Building contractors \\
\hline
\end{tabular}

New roles such as Energy Assessor or Energy Advisor are appearing in relation to this relatively new low carbon built environment. These roles have "...to identify those aspects of the building which need attention to ensure that any adaptions are effective and lead to a real decrease in carbon emissions" [5]. BEST [11] indicates other supporting roles such as those in relation to sales and marketing that will focus on "...communicating the benefits of low carbon and sustainable buildings and processes to consumers and the general public."

About 93\% of employers in the Welsh construction sector have less than 10 employees while less than 1\% are large firms (at least 250 people) [7]. BEST [11] states that training of employees in larger companies is common. Ruiz del Portal et al. [1] suggests that small companies may be reluctant to undertake training due to lack of time, while larger companies, in comparison, are more likely to have the necessary expertise to achieve energy efficient standards. A survey in 2011 [7] showed that although $76 \%$ of employers surveyed had provided access to some form of training for their workforce over the preceding two years, 55\% reported not having taken steps to train staff in respect of low carbon skills. Fortunately this 
is already changing, with literature $[8,12]$ demonstrating that the majority of built environment sector professionals is aware of the fact that operating in a Low Carbon Economy signifies a change in skills and knowledge requirements, with almost $2 / 3$ of respondents in a survey [8] thinking this will be a significant or extensive change. More recently, BEST [11] affirms that "Employers and SME's are likely to be open to training opportunities in order to become familiar with new processes and technologies and compliant with e.g. building regulations..."

Consultation with sector's professionals, as part of the WEST LCBE STNA, explored participants' low carbon knowledge (fig. 1) and the significance of low carbon agenda in their practice (fig. 2) among other questions.

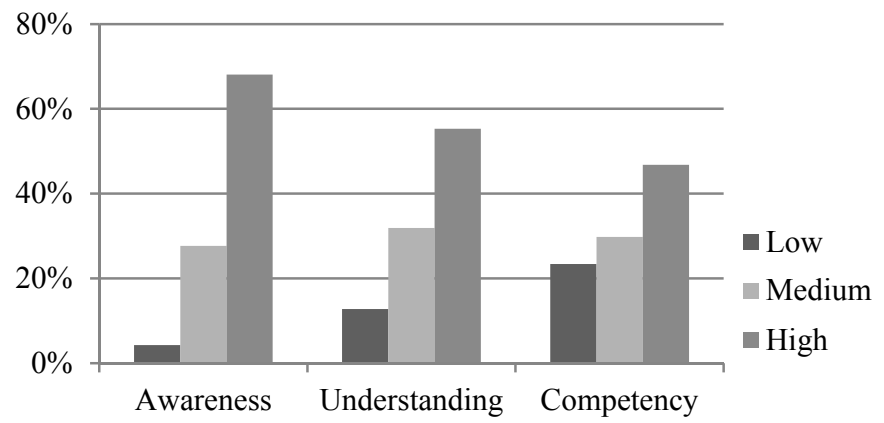

Figure 1: Practitioners' awareness, understanding, and competency in the low carbon agenda, strategies and technologies

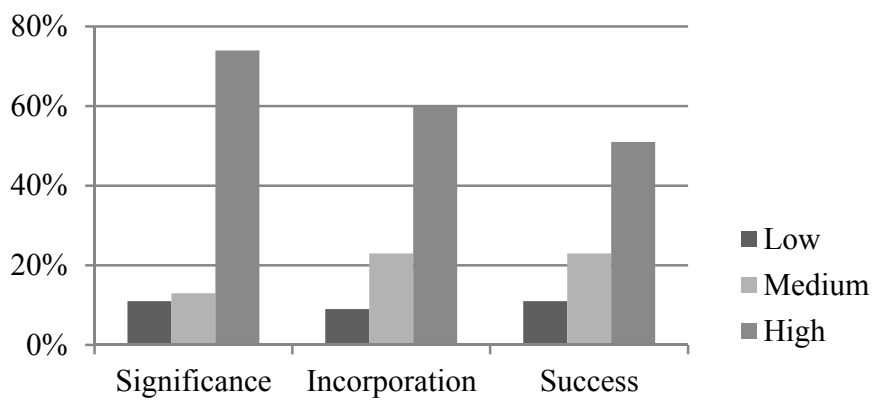

Figure 2: Significance of low carbon agenda, incorporation, and success of low carbon solutions in their practice.

Almost $70 \%$ of respondents considered themselves to have a high level of awareness however only under $50 \%$ recognised a high level of competency.

High level of incorporation $(60 \%)$ and success $(50 \%)$ of low carbon solutions were not reported as frequently as high level of significance (75\%) of low carbon agenda in practice. Those lower percentages are likely linked to the level of competency above. BEST [11] defines a less optimistic picture: "There is a lack 
of capability to deliver...often associated with low level of knowledge and motivation amongst employers... to invest in relevant training."

Considering the age profile (table 2) it is clear that, as others in UK, the Welsh construction industry is ageing, especially in non-manual occupations [7]. This data together with "... a long-standing tendency towards early retirement and difficulties recruiting teaching staff..." highlights the importance of ensuring that capacity within existing training provision remains in order to be able to cope with new trainees in coming years [7]. Likewise, quality must be kept high with lecturers that can keep the industry up-to-date with the changing reality [8].

Table 2: $\quad$ Age profile of construction workforce. Source: ONS. 2012. Labour Force Survey (via [7]).

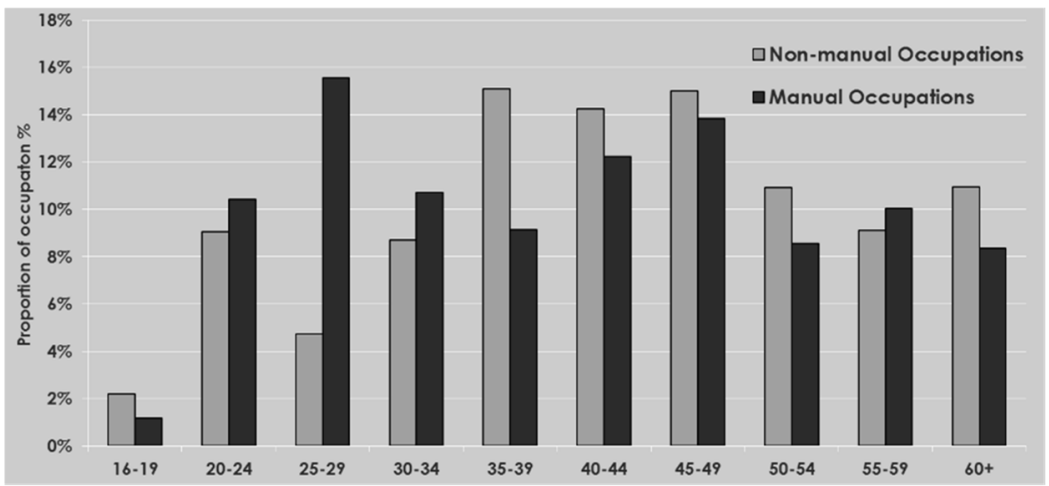

\subsection{Drivers for low carbon skills demand}

Several reports $[5,7,8,13]$ point to legislation as being the most important driver for low carbon skills demand and development. Accordingly, BEST [11] foresees "...increasing pressure on the industry to reduce emissions..." as policy and legislation remain committed to the decarbonisation of the sector.

The Asset Skills et al. [5] identified a significant potential demand from the market for low carbon skills and knowledge. However, while some [7, 13] include market growth and commercial opportunities among the most influential drivers, other authors $[1,5,9]$ report that the industry may be failing to see the long term benefits and the competitiveness that low carbon skills will provide. This awareness would be key for the "...uptake of the low carbon skills training provision beyond legislation requirements" [1] and ultimately for the implementation of the Low Carbon Economy. UK and Welsh Governments have regulatory tools in place to push the standards, however HM Government [9] expects a proactive industry and states "it is essential that the industry drives the demand for skills to ensure they meet market requirements". Industry's leading attitude will be even more critical in the case of existing homes in which legislation is not providing a clear direction. At the same time, industry expects a proactive 
Government to push regulation which drives the skill demand and supports appropriate training. Rudd et al. [14] reports a study where "None of the companies...were of the opinion that they should be leading the drive towards Renewable Energy or a Low Carbon economy. It was firmly seen as the responsibility of the Welsh Government..." The conclusion of the discussion is the polarized perspectives of both administration and industry. CITB [7] warns "...the risk of skills shortages and gaps could remain significant unless action is taken..."

Asset Skills et al. [5] reports consumer attitude as a key factor for future demand together with legislation. However, upfront costs deter both users and developers from playing a more significant role in driving current demand [5]. Ruiz del Portal et al. [1] explains that publicly funded initiatives exist that currently address the economic deterrents. However, given "...the lack of significant uptake...the funding may not be targeting the right goals." Lack of understanding of clients and funding bodies is hinted by Blick [15] as another reason for their modest role as driver for skills demand. "...Energy and carbon compliance is not recognised as a high priority". In this regard Ruiz del Portal et al. [1] suggests "...that a proactive and informed industry may empower clients for the decision making process by trickling down information."

\subsection{Current and prospective training needs}

There is a general agreement $[5,9,11,12]$ on the need for support for both skills and knowledge within the sector. "Capabilities are developed by combining the competency developed through up-skilling with the ability to apply those skills appropriately over time through understanding and knowledge" [11]. However, Asset Skills et al. [5] indicate the difficulty in accurately identifying 'current' skill needs within the rapidly changing requirements. Regardless, “...the industry needs to have a clear understanding of the existing status of low carbon construction skills, [and] the scale and specification of future skills needs..." [9]. The LCBE strand of the WEST project highlighted the following training needs [1]:

- Low carbon economy overview;

- Integrated and holistic approach;

- Fabric First: knowledge and skills;

- Low carbon technologies;

- Alternative materials;

- Retrofit of existing buildings;
- Larger scale than individual building;

- Energy management/‘Soft landing’;

- supply chain;

- Legislation;

- Lifecycle costing.

Low carbon economy overview: literature $[1,8,14]$ agrees that there is a lack of knowledge on the underpinning concept of low carbon, and basic training is needed in Wales to "...provide a general understanding of the changes that the Low Carbon Economy signifies for the built environment sector" [1]. According to Rudd et al. [14] "Low Carbon Economy does not appear to have the greatest importance [within FE provision]... This lack of inclusion reduces the students' ability to appreciate the holistic nature of [these low carbon] concepts, and the global benefits that [these low carbon] strategies could have, if adopted." BEST 
[11] supports the above and advocates an increased carbon literacy for the development of a 'light green workforce'.

Integrated and holistic approach: several authors [1, 9, 11, 12, 16] confirm the need for a holistic approach to the building process where professions and trades are integrated rather than considered in isolation. This approach needs to understand the process of design, construction and maintenance as one with continuation through phases for a successful delivery and performance of low carbon buildings. A holistic and integrated approach will result in a broader understanding of issues beyond specific job roles, an effective development of skills and "... an understanding of the implications of new technology or solutions on other areas of design and build" [11] ultimately reducing whole life carbon emissions from buildings. BIM (Building Information Management) contributes to this approach as it facilitates collaboration and the share of information between different roles and across building life phases. Training in BIM is requested by practitioners [1] and its need has been identified by several authors [7, 11].

Fabric First: knowledge and skills - several authors [5, 9, 15, 16] highlight with different terms (i.e. airtightness, energy/thermally efficient fabric) the need to understand the commonly established rule 'Fabric First'. This strategy is prioritised above other solutions (i.e. low carbon technologies or renewable sources of energy) [5]. Technical requirements such as insulation, airtightness and thermal bridging are part of this Fabric First rule and require not only knowledge and understanding but also technical and detailing skills. BESSCG [16] sets the provision of short training courses in air tightness and external wall insulation for the existing workforce as a priority for action.

Low carbon technologies: understanding low carbon technologies is the first step for their integration in both the retrofitting of existing buildings and the design of new ones [1]. Rudd et al. [14] found that "Installers and suppliers have often been surprised at the specification of unsuitable technologies or installation in unworkable locations." Accordingly, BESSCG [16] includes this training need in their priorities for action. Widening the scope brings us to the next training need.

Energy management and 'soft landing': buildings that integrate low carbon technologies and services are complex systems. Blick [15] stated that it is "Important to understand how buildings are performing in practice" and to make sure that the services are appropriately tuned in order to minimise the gap between the designed and the actual performance of the building. BESSCG [16] reports "...concerns with commissioning of low carbon technologies and systems and the need for skills development in this area." This training need will be linked to the operational phase and roles such as Facilities Manager or Energy Advisor. It is also important to ensure that final users of buildings are aware of its functioning and receive basic advice in order to maintain its efficient performance. NHBC et al. [12] includes the ability for demonstration and handover of properties in the list of future requirements for site managers, in reference to 'soft landing'. 
Alternative materials: Essex and Hirst's [8] survey includes specification of materials among the design skills which gathered more interest from the respondents. WEST LCBE consultation participants [1] mention recycled and alternative materials in their comments. BEST [11] refers to the tendency to use more recycled and carbon neutral materials and states "In Wales there is an increasing emphasis on using local timber as a build product.", and includes skills needs in relation to materials at all phases of the building lifecycle.

Retrofit of existing buildings: there is no doubt that retrofitting is one of the main areas where practitioners need upskilling [1] and comments from consultation respondents confirm that they are aware and willing to uptake training. Asset Skills et al. [5] identifies the "...need to ramp up skills in relation to aspects of fabric such as solid wall insulation and hard to treat properties..." It also points out that "...it is how skills are utilised that is critical, as the wrong application of skills in this area can be damaging."

Supply chain: Asset Skills et al. [5] explains: "Many low carbon industries are inter-related and inter-dependent...Understanding these supply chain linkages and providing effective support... is essential for the development of a strong and vibrant low carbon sector." The knowledge of the "Increasing importance of effective supply chain management" is among future needs for site managers [12].

Larger scale than the individual building: WAG [2] proposes energy generation at community scale as an action to increase energy efficiency and reduce emissions in the residential sector. This requires that "...land use planning decisions are informed by the need to minimise emissions."

Legislation: being the main driver for skills demand, communication of legislation requirements is likely to stimulate the uptake of the Low Carbon Agenda [1]. Surveys $[1,8]$ showed that practitioners are very much interested in knowing about these requirements.

Lifecycle costing: knowing the immediate costing of chosen solutions is important for practitioners. However, "...being able to explain the long term benefits and payback to clients" [1] helps to overcome reluctance and become a catalyst for the implementation of the low carbon economy. Therefore the training on Lifecycle costing $[1,8]$ rather than just capital cost becomes relevant.

\section{Weaknesses in the existing training provision}

Low carbon skills training provision is a relatively recent and growing market. Literature $[7,8,11,13,14,16,17]$ depicts a burgeoning list of public and private initiatives and providers that augment the offer in this sector every day. This includes, without being exhaustive: Universities (Higher Education); Colleges (Further Education); Private Providers; Professional Bodies and Trade 
Associations; Skills Sector Councils and Government funded initiatives; Internal training by Private Companies; Product Specific Training by manufactures. Despite this growing supply Ruiz del Portal et al. [1] suggests that drivers for skills demand may not be stimulating the training provision accordingly. In fact, current provision is not considered sufficient and fit for purpose $[8,16]$ with demand in new and specialist areas that continues to be unmet [7]. The following weaknesses in the existing training provision can be identified.

Scope: according to the literature $[8,14]$, the training that is provided may not be aiming at the wider audience. It focuses only on future professionals and doesn't cater for current practitioners who need to update their knowledge to the new low carbon market. Essex and Hirst [8] affirm: "Courses tend to be too wide and to be focused towards new entrants...In addition, there are limited opportunities for professionals already operating in the professional sector..."

Level of training: there has been an emphasis on more basic manual and lower technical skills to the detriment of higher professional levels [8, 11]. BESSCG [16] states that "Professional skills development is of equal importance as trade skills development, with the need for more professionals to acquire key technical skills for low carbon construction."

Training content: existing training frequently lacks the necessary holistic perspective and fails to provide a broader understanding of the theory underpinning low carbon technologies and its impacts on different roles $[1,16]$. This is a fundamental need identified in the previous section. In addition, $75 \%$ of WEST LCBE survey respondents considered that, due to irrelevant content, among other reasons, available training did not fulfil their requirements to some degree. For those that attended training in the previous year out of date or too basic content and the lack of practical application were reasons for dissatisfaction.

Staff expertise: Rudd et al. [14] reports the lack of sufficient trained staff to deliver Low Carbon Economy related education, particularly in North Wales. CITB [7] states that in order to provide the training not only additional specialised staff would be necessary, also knowledge and skills of current teaching resources would need to improve and be "...supported by access to on-going research and development". This is in clear reference to 'training the trainer' need.

Lack of coordination: BEST [11] reports the lack of a coherent strategy for a coordinated provision of low carbon training in Wales which translates to replication and lack of quality. Essex and Hirst [8] found that outside of formal programmes training courses are generally ad hoc and reactive. These are usually offered without a structure of studies and lack professional accreditation. According to NHBC et al. [12] “...many employers and employees do not know where best to turn to get the skills and knowledge they need." 


\section{WEST contribution to low carbon skills training provision}

WEST is a three year project funded by the European Regional Development Fund, through the Welsh Government that has developed "...a strategy for a targeted and coordinated educational programme for the low carbon energy sector across Wales. Training ... have been developed and piloted, enabling the uptake of the LCRI_EP research by Welsh industry" [18]. Capacity of the WEST project to develop training is limited by the content of LCRI LCBE research:

- Sustainable building envelopes;

- Energy efficient lighting solutions;

Envelopes;

- Timber in building construction;

Lighting;

- Low carbon design;

- Urban scale energy demand and supply;

Timber;

Design;

- Monitoring the energy performance of low carbon buildings;

Urban scale;

- Innovation, technology deployment and market development; Innovation.

Training from LCRI LCBE research has been included in the LCBE course suite (fig. 3) covering skills and knowledge that have been identified by Ruiz del Portal et al. [1] as current or future needs and of interest for practitioners.

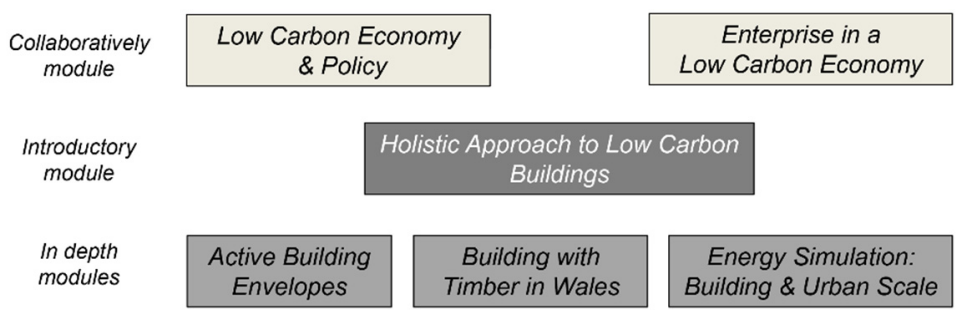

Figure 3: Training topics in WEST LCBE course suite.

Table 3 explains how WEST provision partly addresses existing training needs identified in section 2 .

Table 4 explains how WEST training addresses weaknesses in the existing provision identified in section 3 . 
Table 3: WEST provision against identified training needs.

\begin{tabular}{|c|c|}
\hline & WEST provision \\
\hline & \multirow{2}{*}{$\begin{array}{l}\text { Two overarching topics are included in each of the WEST course } \\
\text { suites: 'Low Carbon Economy and Policies' and 'Enterprise in } \\
\text { the Low Carbon Economy'. Research content from LCBE } \\
\text { Innovation in relation to the understanding of how to set and } \\
\text { strengthen supply chains in the development of the low carbon } \\
\text { sector will be part of these overview courses. }\end{array}$} \\
\hline Supp & \\
\hline & \multirow{3}{*}{$\begin{array}{l}\text { Holistic approach to low carbon buildings. LCBE Design } \\
\text { research content will form the core of this course while } \\
\text { introductory references to the rest of the topics will also be } \\
\text { incorporated. The focus of this research was on the Fabric First } \\
\text { rule for energy efficiency which will address the identified } \\
\text { training need on this topic. The course will also address the } \\
\text { theory underpinning the implementation of low carbon } \\
\text { technologies in the building design. }\end{array}$} \\
\hline & \\
\hline & \\
\hline & $\begin{array}{l}\text { Active building envelopes. This course will include content from } \\
\text { Envelopes research, a topic that has gathered major interest in } \\
\text { the WEST LCBE survey [1]. This course partly addresses the } \\
\text { need for training regarding the understanding of different low } \\
\text { carbon technologies. }\end{array}$ \\
\hline $\begin{array}{l}\text { Energy } \\
\text { managem } \\
\text { and 'soft }\end{array}$ & \\
\hline & $\begin{array}{r}\text { on to } \\
\text { s one } \\
\text { has } \\
\text { ining }\end{array}$ \\
\hline & $\begin{array}{l}\text { ver, } \\
\text { ting }\end{array}$ \\
\hline & $\begin{array}{l}\text { Energy simulation: building and urban scale. This course, } \\
\text { featuring Urban Scale research content may help address skills } \\
\text { for the delivery of Government proposed actions to tackle carbon } \\
\text { emission reduction on a scale beyond the individual building. } \\
\text { WEST survey [1] identified Urban Scale as the LCBE topic that } \\
\text { practitioners had least knowledge about. }\end{array}$ \\
\hline & \multirow{2}{*}{$\begin{array}{l}\text { The capacity of the project to develop training is limited to the } \\
\text { content of the LCRI_CEP LCBE research. Legislation is } \\
\text { formally excluded as a result of funding, while Lifecycle costing } \\
\text { was not subject to LCRI CLBE research. }\end{array}$} \\
\hline & \\
\hline
\end{tabular}


Table 4: WEST provision against existing provision weaknesses.

\begin{tabular}{|l|l|}
\hline \multicolumn{1}{|c|}{ Weaknesses } & \multicolumn{1}{|c|}{ WEST provision } \\
\hline Scope & Targets employees in the Welsh workforce \\
\hline Level of training & Designed for managerial and professional level \\
\hline Training content & See table 3 above \\
\hline Staff expertise & $\begin{array}{l}\text { Delivered by academic staff, that are informed and } \\
\text { supported by recent research, in collaboration with } \\
\text { industry experts. }\end{array}$ \\
\hline $\begin{array}{l}\text { Lack of } \\
\text { coordination. }\end{array}$ & $\begin{array}{l}\text { Development of courses was informed by STNA to } \\
\text { address training needs and avoid replication. The courses } \\
\text { will be offered as both short CPD sessions, 1 credit } \\
\text { courses and 10 credit modules making up the WEST } \\
\text { LCBE course suite (fig. 3). These courses cover basic } \\
\text { through to more specialised levels of knowledge in the } \\
\text { field and can build up towards a higher education } \\
\text { qualification over time [1]. }\end{array}$ \\
\hline
\end{tabular}

\section{Conclusions}

Although professionals in the Welsh building sector generally declare awareness of the low carbon agenda and recognise its significance to their practice, their capability to deliver successful solutions has been found to be limited. While it may be the case that small practices, which are the vast majority in Wales, are more in need of upskilling than larger companies, seizing the opportunity for growth that the low carbon agenda represents for the building sector will depend on the industry's willingness to upskill and be prepared to deliver market requirements. Professionals in need of upskilling are present at every phase of the building lifecycle, from 'design and plan' through 'build' to 'manage and use', and even beyond the specific building sector. 'Training the trainers' is a recommended strategy to keep the quality of training high as well as to ensure its continuation in the future. In fact, existing training provision accumulates a number of weaknesses that will need to be solved in order to effectively contribute to the implementation of the low carbon agenda. It can be seen that the structured training suite and strategy proposed by the WEST project offers LCBE training that aims to respond to these weaknesses while addressing the emerging training needs associated with the low carbon economy. It is argued here that this coordinated approach offer potential to ensure that training responds to the needs of industry - however the evaluation of its success will be the necessary next phase of work.

\section{References}

[1] Ruiz del Portal A, Banteli A, Gwilliam J, Stevenson V. 2014. Skills and Training Needs Analysis: Low Carbon Built Environment. www.westproject.org.uk 
[2] Welsh Government 2012. One Wales: One planet. The Sustainable Development Annual Report 2011-2012. wales.gov.uk

[3] Welsh Government. 2012. Energy Wales: A Low Carbon Transition. wales.gov.uk

[4] WAG. 2010. Climate Change Strategy for Wales. wales.gov.uk

[5] Asset Skills et al. 2009. Low Carbon Cluster. Assessment Report. www.lantra.co.uk

[6] European Commission. 2013. Science for Environment Policy. Thematic issue: Green Construction. Issue 38. ec.europa.eu

[7] CITB. 2013. Skills Needs Analysis of the Construction and Built Environment Sector in Wales. Theme: Onsite and offsite construction in Wales. (draft) to be published on www.best.cf.ac.uk

[8] Essex R. and Hirst C. 2011. Low carbon skills requirements for the regeneration and built environment professional services sector in Wales. www.regenwales.org

[9] HM Government. 2011. Low Carbon Construction Action Plan: Government response to the Low Carbon Innovation and Growth Team report. www.bis.gov.uk

[10] WEST. Quotes from Steering Committee. www.westproject.org.uk

[11] BEST 2014. Built Environment Sustainability Training (BEST). A Strategy for Growth, Adaptation, and Progression. (draft) to be published on www.best.cf.ac.uk

[12] NHBC, Zero Carbon Hub and Construction Skills. 2010. Home Building Skills 2020. Report and recommendations. Home Building Skills. www.zerocarbonhub.org

[13] Pye Tait Consulting. 2011. Skills Provision for the Construction Sector in Wales. Research to inform Transformational Change. www.citb.co.uk

[14] Rudd L., Cullis M., Skydmore D. and Cheeseborough D. 2014. Review of Further Education level training to support the Welsh Government's drive towards a Low Carbon Economy. www.westproject.org.uk

[15] Blick C. 2012. Changes to the Building Regulation in Wales. 2012 Consultation. Part L Conservation of Fuel and Power. Compliance and Performance. Welsh Government. Construction Unit. www.youtube.com

[16] BESSCG, 2012. Delivering low carbon skills. Final Report. cutcarbon.info

[17] Banteli A., Du Plooy A., Gwilliam J.A. and Stevenson V. 2013. Higher Education Report. Executive Summary. www.westproject.org.uk

[18] LCRI, Welsh Energy Sector Training. www.lcri.org.uk 